\title{
Quality of Life among Patients with Acute Coronary Syndrome
}

\author{
Mohannad A. Aljabery ${ }^{1}$, Ahmad R. Saifan ${ }^{2}$, Mohannad Eid AbuRuz ${ }^{3}$, Rami \\ Masa'Deh 4, Haneen M. Abu Hayeah 5 \\ ${ }^{1}$ (Clinical Nurse Specialist / Ministry of health, Jordan) (corresponding author) \\ ${ }^{2}$ (Associate professor, Department of adult health and critical care, Faculty of Nursing, Fatima College for \\ health science, Abu Dhabi, UAE) \\ ${ }^{3}$ (Associate professor, Department of clinical nursing, Faculty of Nursing, Applied Science Private University, \\ Jordan) \\ 4(Associate professor, Department of psychiatric nursing, Faculty of Nursing, Applied Science Private \\ University, Jordan) \\ 5(Clinical Nurse Specialist / Ministry of health, Jordan)
}

\begin{abstract}
Objectives: The purposes of this study were to describe the quality of life for patients with acute coronary syndrome in Jordan, identify the mostly affected quality of life domains and if there was an association between quality of life socio-demographic and clinical characteristics.

Methods: A non-experimental descriptive cross-sectional correlational design was used with a convenience sample of 372 patients with acute coronary syndrome. Data were collected from six different hospitals in Amman city by a self-reported questionnaire.

Results: Overall, the patients' quality of life mean score for all domains was low $(4.06 \pm 1.16)$. The physical domain was the most affected ( $3.87 \pm 1.28)$, followed by the emotional $(4.21 \pm 1.18)$ and lastly is the social domain $(4.26 \pm 1.25)$. There were statistically significant differences in quality of life scores according to gender, level of education, employment status, physically activity, history of dyslipidemia and medical diagnosis.

Conclusion: The results of this study indicated that Jordanian patients with acute coronary syndrome have poor quality of life especially in the physical domain. Social domain of their quality of life was the least affected indicating that there is a strong family support and relation. Different treatments to improve quality of life for those patients are warranted.
\end{abstract}

Keywords: Acute Coronary Syndrome, Jordan, Myocardial infarction, Unstable Angina, Quality of life.

\section{Introduction}

Acute Coronary Syndrome (ACS) is a Cardiovascular Disease (CVD) that occurs due to atherosclerosis (1). Acute Coronary Syndrome refers to a group of signs and symptoms compatible with acute myocardial ischemia (2). It includes unstable angina (UA), non-ST elevation myocardial infarction (NSTEMI) and ST elevation myocardial infarction (STEMI) (3,4). Acute Coronary Syndrome is one of the leading causes of death and disability worldwide, accounting for approximately seven million deaths and 129 million disabilities annually $(5,6)$. Acute Coronary Syndrome affects many aspects of patient's life including, including: physical, psychological, emotional and social (7) .

Quality of life is a diverse phenomenon and is generally understood in terms of how patients perceive their physical, mental and social life in relation to their illness and treatment (8). In patients with ACS, quality of life is usually used to measure the impact of ACS and its treatment on patients' perceptions to their physical, emotional and social functioning over time (9). Assessing these functioning domains addresses what type of care is needed to maintain patients' physical, mental, emotional and social status (10).

Most of the studies about quality of life for patients with ACS were done in developed countries. The results of these studies may or may not be applicable to the people at the developing countries. Moreover, ACS is responsible for the majority of the CVDs deaths worldwide including Jordan $(5,6)$. Therefore, the major purpose of this study was to describe the QoL for patients with ACS in Jordan. Furthermore, the study aims to identify the mostly affected quality of life domains and if there was an association between quality of life, sociodemographic and clinical characteristics.

\section{Methods}

\section{A. Design}

A non-experimental descriptive cross-sectional design was used to meet the objective of this study. 


\section{B. Setting}

The health care system in Jordan includes four major sectors: ministry of health, royal medical services, private sector and the teaching. For the purpose of representative sampling, six hospitals (two public, one military, one teaching and two private) were selected. These sites are covering the whole country and considered as tertiary care centers for heart diseases.

\section{Ethical considerations}

The study was approved by the Institutional Review Board (IRB) committee from the University and all hospitals prior to data collections.

\section{Sample and Sampling}

A non-random convenience sample was used to recruit patients. All patients who met the flowing inclusion criteria were invited to participate: a) diagnosed of ACS (MI or UA), b) Older than 18 years, c) Mentally and hemodynamic stable, d) have no chronic diseases except hypertension (HTN), diabetes mellitus (DM) and dyslipidemia, e) able to read and write Arabic, f) signed an informed consent.

To make sure that the sample size is sufficient to get statistically significant results, sample size was calculated using power analysis software with a power of 0.8 and a medium effect size, and an $\alpha$ of 0.05 . Based on these criteria a sample size of 300 patients was enough to detect a significant result. A total of 410 patients were approached; 390 patients consented and agreed to participate in the study. Among those 372 returned the questionnaire and were included in the final analyses ending with a response rate of $90.73 \%$.

\section{Measurements}

Quality of life was measured by the Arabic version of MacNew heart disease health related Quality of life (MacNew): This instrument specifically measures quality of life for patients with heart diseases. This instrument consists of 27 items distributed on three major domains (physical, emotional and social). The participants rate their response on a likert scale for each item form one to seven. The global score for the instrument range from 7 to 189. After that the mean of the global score was calculated ending with a minimum score of one, indicating low QoL and maximum score of seven, interpreted as high QoL. For the physical domain the score was calculated by the mean score of the 13 items representing the domain. The emotional domain was calculated by the mean score of the 14 items representing the domain. The social domain was calculated by the mean of the 13 items representing the domain. It is necessary to note that there are some items included in more than one domain. MacNew provides a normative reference data which recently updated and published to help authors to interrupting their study result (11).

The Arabic version of this instrument has very good psychometric proprieties. Rawas (2015) reported that the Arabic version of the MacNew had an internal consistency (Cronbach's alpha) of $\geq 0.91$ for each domain of the MacNew and the global score. Moreover, the results of test retest reliability on a sample of 58 patients ranged from 0.81 to 0.87 . The conclusion of this study was that the Arabic version of $t$ the MacNew is valid and reliable.

Socio-demographic and clinical characteristics check list was used to collect information about patient's medical diagnosis, age, gender, marital status, educational level, employment status, exercise level, body mass index (BMI), and chronic illnesses.

\section{Data Analysis}

Data was analyzed using the Statistical Package for the Social Sciences (SPSS 21). Before proceeding with the analysis, a reliability of the questionnaire was checked and a Cronbach alpha was 0.92. Consequently, the reliability for each domain was checked and a Cronbach alpha was 0.88 for physical domain, 0.87 for both emotional and social domains, suggesting a high reliability of all items combined and each domain.

Descriptive statistics (frequencies, means, percentages, and standard deviations) were used to describe the sample characteristics. Independent sample t-test and one way ANOVA were used to identify any significant difference in QoL according to patients' socio-demographic and clinical characteristics.

\section{Results}

Socio-demographics and clinical characteristics of the sample $(\mathrm{N}=372)$ are presented in table 1 . The age of the patients ranged from 30 to 83 years, with a mean age of approximately 55 years. Most of the patients were married $(86.8 \%)$, male $(67.2 \%)$ and working (59.7\%). Approximately $42.7 \%$ of the patients had secondary school and below and $26.3 \%$ had high school qualifications. More than two third of the participants were categorized as overweight and obese and only one fifth of the sample reported conducting regular exercise. More than half of the patients (54.8\%) were suffering from HTN, 40.6\% had DM and 54.0\% reported dyslipidemia. 


\section{<Table 1 here>}

\section{E. Quality of life of Jordanian patients with ACS}

The global score of the QoL was $(4.06 \pm 1.16)$. The physical domain was the domain with the lowest score (3.87 $\pm 1.28)$, followed by emotional ( $4.21 \pm 1.18)$ and finally, the social domain $(4.26 \pm 1.25)$.

F. Differences in QoL according to patients' socio-demographics and clinical characteristics

Quality of life global score significantly differed among different medical diagnosis, gender, employment status, dyslipidemia, exercise and educational status of the patient. Patients diagnosed with MI had significantly higher QoL global score than those diagnosed with UA $(4.23 \pm 1.07$ vs. $3.78 \pm 1.13, \mathrm{t}(3.877), \mathrm{P}<0$.001). Additionally, female patients had significantly lower QoL global score than male patients $(3.66 \pm 1.08$ vs. 4.25 $\pm 1.08 ; \mathrm{t}(-4.893), P<0.001)$.

Furthermore, unemployed patients had significantly lower QoL MacNew global score than employed patients $(3.76 \pm 1.06$ vs. $4.26 \pm 1.11, \mathrm{t}(-4.361), P<0.001)$. Moreover, the study reported that the patients having dyslipidemia in their medical history had significantly lower QoL MacNew global score than those who did not have dyslipidemia $(3.85 \pm 1.08$ vs. $4.29 \pm 1.11, \mathrm{t}(-3.856), P<0.001)$. Finally, the study found that the patients who did not practice exercise had significantly lower QoL MacNew global score than patients who did practice exercise $(3.91 \pm 1.08$ vs. $4.60 \pm 1.09, \mathrm{t}(-4.955), P<0.001)$.

The global scores of QoL of patients did not differ among the remaining socio-demographic and clinical characteristics (age, marital status, BMI, HTN and DM).

Tables 2 and 3, illustrates the impact of educational level on patients' QoL. Results indicated that there was a statistically significant main effect for the educational level: $[f(4,367)=8.90, P<0.001]$. Post-hoc comparison tests indicated that patients who had secondary school and below were responsible for the main effect. The QoL MacNew global score for this group was significantly lower than postgraduate groups.

<Table 2 here>

$<$ Table 3 here>

\section{Discussion}

This is the first study that was designed specifically to describe the QoL for patients with ACS in a developing country; Jordan. The findings showed that the mean global score was $(4.06 \pm 1.16)$. This result indicated that those patients have poor QoL because these scores are lower than the scores of many studies around the globe with similar health conditions. The mean global score ranged from $(4.66 \pm 1.0)$ in Eastern Europe to ( $5.29 \pm 1.0)$ in Scandinavia (12). Furthermore, the mean global score in this study was also lower than the mean global scores obtained from patients in many countries such as Canada, United States, Switzerland, Austria, Brazil and Turkey (13-16).

These results could be from the seriousness of ACS diagnosis and its link with death in many cases (17). Difference in health care systems among countries and the resources provided for patients may affect their QoL (18). Cultures differences and living context may impair QoL in normal people among countries. Compared to the developed countries, Jordan as a developing country has limited resources and health insurance to the citizens. Moreover, Jordan is considered one of the most expensive countries not only in the Middle East but all over the world compared to the income. Taking all these factors into consideration, no wonder that Jordanian patients with ACS have poor QoL scores in comparison with patients from other countries.

Among the three QoL domains, the physical domain had the lowest QoL score. These results are compatible with other studies $(19,20)$. As documented in other studies, the ACS signs and symptoms affect patents' physical functions and impair their physical ability $(21,22)$. Having a diagnosis of ACS represents a life-threatening event that may result in physical limitations due to the signs and symptoms of the disease (e.g. chest pain, difficulty in breathing, and the inability to perform a physical activity). Acute coronary syndrome may also result in emotional and social impaired functioning due to feelings associated with fears from death and losing families (i.e. inability to maintain family commitments and relationships) (23). It seems logical for participants to report low QoL scores in the physical domain, because of the illness-related factors mentioned above, and the fact that around $80 \%$ of the patients have never been engaged in any physical exercises. This result is supported by another Jordanian study (24), which aimed to assess the learning needs among ACS patients. Eshah (24) indicated that participants did not recognize the importance of physical exercise to improve their physical functioning and they classified it as a low priority among other needs.

The other two domains (social and emotional) were presented with similar QoL global score and they were higher than the score for the physical domain. These findings contradict the results of other authors (16), which reported that the disease impacts on QoL were the same across the different domains. However, other studies reported that the social domain had the highest score in comparison to the physical and emotional domains $(25,26)$. However, this study did not corroborate those findings, possible due to the underlying Jordanian cultural domain. Jordanians tend to hide their emotional feelings during illness from their families and the public, and they try to avoid asking for social and emotional support (27). Additionally, Jordanian patients 
usually receive good support as a matter of course from their relatives, especially first-degree relatives, based on the religious and socio-cultural purposes (27). It should be noted that while the social and emotional domains obtained better scores than the physical, these were still lower scores of the global studies (12). This could partly result from the shortage in informational programs and rehabilitation services in Jordan. Eshah (24) reported that Jordanian patients with ACS indicated a high need for information about their ACS diagnosis before being discharged from the hospitals. This shortage in information may affect their adaptation process with the new situation and may decrease their chances to learn about their disease and how to adopt a healthy lifestyle (28).

The study found that QoL global score among UA patients was significantly lower than MI patients. This result seems to be in agreement with the findings of some other studies $(29,30)$. The clinical characteristics presented among UA versus MI patients may explain these findings. Unstable Angina patients experience several anginal attacks that increase in intensity over time. They also experience recurrent cardiac events and they have more co-morbidities and extensive coronary diseases that result in long term prognosis associated with poorer health status $(31,32)$. Myocardial infarction is always more severe than UA and is a life-threatening episode, which mandate the patients to seek immediate medical treatment and therapeutic management. This medical and therapeutic management may positively impact their QoL, contrary to UA patients, whose conditions result in delayed or less medical attention and consequently result in lowering their QoL (30).

Consequently, findings showed that male patients scored higher QoL than female patients. This result is consistent with other studies $(33,34)$. Female patients usually show lower level of coping with illness compared to male patients and they use different coping mechanism (35). Other researchers reported that the complications of ACS are greater in female patients than in male patients (36). The complications of the disease may lead to worse outcomes and therefore lower level of QoL (37). Furthermore, female patients are usually more depressed following ACS events compared to male patients. This depression negatively affects the QoL for females compared to males $(38,39)$.

Unemployed patients reported lower QoL MacNew global score than employed patients. This is supported by another research study that examined the impact of working status on QoL for patients with coronary heart disease (40). This finding could be caused by the functional limitations and physical deficiencies caused by the disease, which may affect patients' ability to work. The ACS clinical presentations (e.g. chest pain and shortness of breath) directly affect patients' ability to perform tasks related to daily life activities such as working (33). Consequently, the perception of inability to work among non-working patients may affect their lifestyle and their self-image, and hence their QoL. Yuval, Halon \& Lewis (41) examined ACS patients' perceptions toward lifestyle changes and their desire to return back to work after being discharged from hospital and reported that the majority of patients expressed low confidence levels, poor self-image, high anxiety level and major impact on their lifestyle. The study concluded that ACS traumatically affected those patients and resulted in prolonged changes in their lifestyle which negatively affected their desire to return to work and significantly compromised their QoL.

In line with previous studies, the result of this study showed that the global MacNew score for the patients with dyslipidemia was significantly lower than for those without dyslipidemia (42-44). Different possible explanations exist in the literature. One of them is that cholesterol was identified as one of the CVDs risk factors and it is considered to be a major cause of atherosclerosis (45). Montalescot et al. (46) identified that the untreated dyslipidemia as the strongest predictor of hospital deaths among patients suffering from ACS. Another explanation is that dyslipidemia is associated with a generally unhealthy lifestyle; patients with dyslipidemia are usually obese, physically inactive, and have unhealthy eating habits (47). Based on this, increasing the prevalence rate of dyslipidemia among ACS patients may be correlated with unhealthy lifestyle and may develop physical and psychological disorders or other cardiac complications which may affect patients' QoL $(28,48)$.

The mean global MacNew score for patients who were physically inactive and not performing exercises was lower than those patients who used to do exercise. Several studies supported this finding (49-51). Physical inactivity is considered to be a behavioral risk factor in CVDs, and a lifestyle component that is associated with poor prognosis in ACS as well as QoL (50, 52, 53). Adjustment for these factors through lifestyle modification, such as increasing sport activities, has a great effect on the patients' health status and leads to better QoL outcomes $(52,54-57)$. The current study found that patients who were physically inactive had higher prevalence rates of HTN (56.4\%) and dyslipidemia (57.8), which may have compromised their health status and affected their QoL.

Finally, the study reported that patients with secondary school educational level and below scored the lowest mean global MacNew score, while those with postgraduate education scored the highest. This shows that the higher the educational level, the higher the QoL, corroborating the findings of previous studies $(36,49,58$ 60). Low educational level was associated with poor perception of the disease and its risk factors. Patients with lower levels of education may face difficulties in reading, understanding or following instructions given in the 
hospitals or presented in their medication leaflets. This might be associated with misuse of their medication or decreased awareness toward healthy lifestyles, which may affect their health status and their QoL $(58,61,62)$.

\section{Conclusions}

The present study identified that the Jordanian ACS patients had impaired QoL in general and in the three domains. Among these domains, the physical domain was the mostly impaired; while approximately similar mean scores for both emotional and social domains were observed. Consequently, the study found that QoL level differs among some socio-demographic and clinical characteristics of the participants. Finally, the Arabic version of the MacNew QoL was found to be applicable to cardiac patients in the Jordanian community. Competing interests

The authors declare that they have no competing interests

II. TABLES

Table 1: Socio-demographics and clinical characteristics of the patients $(n=372)$

\begin{tabular}{|c|c|}
\hline Characteristics & Mean $=$ SD or $\%(N)$ \\
\hline Global score: & $4.06=1.16$ \\
\hline Physical score & $3.87=1.28$ \\
\hline Emotional score & $4.21=1.18$ \\
\hline Social score & $4.26=1.25$ \\
\hline \multicolumn{2}{|l|}{ Medical diagnosis: } \\
\hline Unstable angina & $39.0 \%(145)$ \\
\hline Myocardial infarction & $61.0 \%(227)$ \\
\hline Age (years) & $55.20=10.45$ \\
\hline \multicolumn{2}{|l|}{ Gender: } \\
\hline Male & $67.2 \%(250)$ \\
\hline Female & $32.8 \%(122)$ \\
\hline BMII & $28.48=5.82$ \\
\hline \multicolumn{2}{|l|}{ Employment status: } \\
\hline Yes & $59.7 \%(222)$ \\
\hline No & $40.3 \%(150)$ \\
\hline \multicolumn{2}{|l|}{ Dyslipidemia: } \\
\hline Yes & $54.0 \%(201)$ \\
\hline No & $46.0 \%(171)$ \\
\hline \multicolumn{2}{|l|}{ Exercises: } \\
\hline $\begin{array}{l}\text { Yes } \\
\text { No }\end{array}$ & $\begin{array}{l}20.4 \%(76) \\
79.6 \%(296)\end{array}$ \\
\hline \multicolumn{2}{|l|}{ High blood pressure: } \\
\hline Yes & $54.8 \%(204)$ \\
\hline No & $45.2 \%(168)$ \\
\hline \multicolumn{2}{|l|}{ Diabetes: } \\
\hline Yes & $40.6 \%(151)$ \\
\hline No & $59.4 \%(221)$ \\
\hline \multicolumn{2}{|l|}{ Marital status: } \\
\hline Single & $3.2 \%(12)$ \\
\hline Married & $86.8 \%(323)$ \\
\hline Divorced & $2.7 \%(10)$ \\
\hline Widowed & $7.3 \% \quad 27)$ \\
\hline \multicolumn{2}{|l|}{ Educational level: } \\
\hline Secondary school and below & $42.7 \%(159)$ \\
\hline High school & $26.3 \%(98)$ \\
\hline Diploma & $12.4 \%(46)$ \\
\hline B.Sc & $14.0 \%(52)$ \\
\hline Post graduate & $4.6 \%(17)$ \\
\hline \multicolumn{2}{|l|}{ BMII categories: } \\
\hline Underweight & $1.6 \%(6)$ \\
\hline Normal & $25.3 \%(94)$ \\
\hline Overweight & $37.4 \%(139)$ \\
\hline Obesity & $35.8 \%(133)$ \\
\hline
\end{tabular}


Table 2: Difference in QoL MacNew global score according to educational level of the patients $(\mathrm{n}=372)$

\begin{tabular}{|l|l|l|l|l|}
\hline Educational level & N & Mean \pm SD & F & p-value \\
\hline Secondary school and below & 159 & $3.7407 \pm 1.15$ & \multirow{2}{*}{8.90} & $P<0.001$ \\
\cline { 1 - 3 } High school & 98 & $4.0306 \pm 0.98$ & & \\
\cline { 1 - 3 } Diploma & 46 & $4.4089 \pm 0.94$ & \\
\hline B.sc & 52 & $4.5518 \pm 1.11$ & \\
\cline { 1 - 3 } Post graduate & 17 & $4.6719 \pm 1.04$ & \\
\cline { 1 - 3 } \\
Note: SD= standard deviation. N= number of participants \\
The table above presented the result of one way ANOVA
\end{tabular}

Table 3: Post-hoc test of QoL MacNew global score across different educational level $(\mathrm{n}=372)$

\begin{tabular}{|l|l|l|l|}
\hline Educational level & $\begin{array}{l}\text { Mean difference in the } \\
\text { educational level }\end{array}$ & P-value \\
\hline \multirow{4}{*}{ Secondary school and below } & High school & -0.29 & 0.219 \\
\cline { 2 - 4 } & Diploma & -0.67 & $<0.01$ \\
\cline { 2 - 4 } & B.Sc & -0.81 & $<0.001$ \\
\cline { 2 - 4 } & Post Graduate & -0.93 & $<0.01$ \\
\hline \multirow{5}{*}{ High school } & Secondary & 0.29 & 0.219 \\
\cline { 2 - 4 } & Diploma & -0.38 & 0.280 \\
\cline { 2 - 4 } & B.Sc & -0.52 & $<0.05$ \\
\cline { 2 - 4 } & Post Graduate & -0.64 & 0.154 \\
\hline \multirow{5}{*}{ Diploma } & Secondary & 0.67 & $<0.01$ \\
\cline { 2 - 4 } & High school & 0.38 & 0.280 \\
\cline { 2 - 4 } & B.Sc & -0.14 & 0.965 \\
\cline { 2 - 4 } & Post Graduate & -0.26 & 0.909 \\
\hline & Secondary & 0.81 & $<0.001$ \\
\cline { 2 - 4 } & High school & 0.52 & $<0.05$ \\
\cline { 2 - 4 } & Diploma & 0.14 & 0.965 \\
\cline { 2 - 3 } & Post Graduate & -0.12 & 0.995 \\
\hline \multirow{5}{*}{ Post Graduate } & Secondary & 0.93 & $<0.01$ \\
\cline { 2 - 3 } & High school & 0.64 & 0.154 \\
\cline { 2 - 3 } & Diploma & 0.26 & 0.909 \\
\cline { 2 - 3 } & B.Sc & 0.12 & 0.995 \\
\hline
\end{tabular}

\section{References}

[1]. Amsterdam EA, Wenger NK, Brindis RG, Casey DE, Jr., Ganiats TG, Holmes DR, Jr., et al. 2014 AHA/ACC Guideline for the Management of Patients with Non-ST-Elevation Acute Coronary Syndromes: a report of the American College of Cardiology/American Heart Association Task Force on Practice Guidelines. Journal of the American College of Cardiology. 2014;64(24):e139-228.

[2]. Smith JN, Negrelli JM, Manek MB, Hawes EM, Viera AJ. Diagnosis and management of acute coronary syndrome: an evidencebased update. Journal of the American Board of Family Medicine 2015;28(2):283-93.

[3]. Kumar A, Cannon CP, editors. Acute coronary syndromes: diagnosis and management, part I. Mayo Clinic Proceedings; 2009: Elsevier.

[4]. Anderson JL, Adams CD, Antman EM, Bridges CR, Califf RM, Casey DE, et al. 2011 ACCF/AHA focused update incorporated into the ACC/AHA 2007 guidelines for the management of patients with unstable angina/non-ST-elevation myocardial infarction a report of the american college of cardiology foundation/american heart association task force on practice guidelines. Circulation. 2011;123(18):e426-e579.

[5]. Vedanthan R, Seligman B, Fuster V. Global Perspective on Acute Coronary Syndrome A Burden on the Young and Poor. Circulation research. 2014;114(12):1959-75.

[6]. WHO. Jordan: WHO statistical profile. Country statistics and global health estimates by WHO and UN partner; 2015.

[7]. Dessotte CAM, Dantas RAS, André S. Patients' symptoms before a first hospitalization due to Acute Coronary Syndrome. Revista da Escola de Enfermagem da USP. 2011;45(5):1097-104.

[8]. Bowling A. Health-related quality of life: A discussion of the concept, its use and measurement background: The'Quality of Life'Presented to the Adapting to Change Core Course, September 1999. 2013.

[9]. Leung Yinko SSL, Pelletier R, Behlouli H, Norris CM, Humphries KH, Pilote L. Health-related quality of life in premature acute coronary syndrome: does patient sex or gender really matter? Journal Of The American Heart Association. 2014;3(4).

[10]. Beck CA, Joseph L, Bélisle P, Pilote L, Investigators Q. Predictors of quality of life 6 months and 1 year after acute myocardial infarction. American heart journal. 2001;142(2):271-9.

[11]. Höfer S, Turk-Adawi K, Oldridge N. The MacNew heart disease health-related quality of life questionnaire: Updated reference data for users. European Journal for Person Centered Healthcare. 2016;4(1):221-9.

[12]. Höfer. S, Turk-Adawi. K, Oldridge. N. The MacNew heart disease health-related quality of life questionnaire: Updated reference data for users. 2015.

[13]. Hofer S, Saleem A, Stone J, Thomas R, Tulloch H, Oldridge N. The MacNew Heart Disease Health-Related Quality of Life Questionnaire in patients with angina and patients with ischemic heart failure. Value in health : the journal of the International Society for Pharmacoeconomics and Outcomes Research. 2012;15(1):143-50.

[14]. Silva SAd, Passos SRL, Carballo MT, Figueiró M. Avaliação da qualidade de vida após síndrome coronariana aguda: revisão sistemática. Arquivos Brasileiros de Cardiologia. 2011;97:526-40.

[15]. Yu DS, Thompson DR, Yu CM, Oldridge NB. Validation of the Chinese version of the MacNew heart disease health-related quality of life questionnaire. Journal of evaluation in clinical practice. 2008;14(2):326-35. 
[16]. Kahyaoglu Sut H, Unsar S. Is EQ-5D a valid quality of life instrument in patients with acute coronary syndrome? Anadolu kardiyoloji dergisi : AKD = the Anatolian journal of cardiology. 2011;11(2):156-62.

[17]. Pragodpol P, Ryan C. Critical review of factors predicting health-related quality of life in newly diagnosed coronary artery disease patients. Journal of Cardiovascular Nursing. 2013;28(3):277-84.

[18]. Bambra C, Fox D, Scott-Samuel A. Towards a politics of health. Health Promotion International. 2005;20(2):187-93

[19]. Rumsfeld JS, Magid DJ, Plomondon ME, Sales AE, Grunwald GK, Every NR, et al. History of depression, angina, and quality of life after acute coronary syndromes. American heart journal. 2003;145(3):493-9.

[20]. Seo J, Lee Y, Kang S, Chun H, Pyun WB, Park SH, et al. Poor health-related quality of life and proactive primary control strategy may act as risk factors for acute coronary syndrome. Korean circulation journal. 2015;45(2):117-24.

[21]. Swenson JR, Clinch JJ. Assessment of quality of life in patients with cardiac disease: the role of psychosomatic medicine. Journal of psychosomatic research. 2000;48(4):405-15.

[22]. Rančić N, Petrović B, Apostolović S, Kocić B, Ilić M. Health-related quality of life in patients after the acute myocardial infarction. Open Medicine. 2013;8(2)

[23]. Chodosh J, Morton SC, Mojica W, Maglione M, Suttorp MJ, Hilton L, et al. Meta-analysis: chronic disease self-management programs for older adults. Annals of internal medicine. 2005;143(6):427-38.

[24]. Eshah NF. Jordanian acute coronary syndrome patients' learning needs: Implications for cardiac rehabilitation and secondary prevention programs. Nursing \& health sciences. 2011;13(3):238-45.

[25]. Kim J, Henderson RA, Pocock SJ, Clayton T, Sculpher MJ, Fox KA. Health-related quality of life after interventional or conservative strategy in patients with unstable angina or non-ST-segment elevation myocardial infarction: one-year results of the third Randomized Intervention Trial of unstable Angina (RITA-3). Journal of the American College of Cardiology. 2005;45(2):2218.

[26]. Kiebzak GM, Pierson LM, Campbell M, Cook JW. Use of the SF36 general health status survey to document health-related quality of life in patients with coronary artery disease: effect of disease and response to coronary artery bypass graft surgery. Heart \& Lung: The Journal of Acute and Critical Care. 2002;31(3):207-13.

[27]. AbuRuz ME, Alaloul F, Saifan A, Masa'deh R, Abusalem S. Quality of Life for Saudi Patients With Heart Failure: A CrossSectional Correlational Study. Glob J Health Sci. 2015;8(3):45752.

[28]. Eshah NF. Predischarge education improves adherence to a healthy lifestyle among Jordanian patients with acute coronary syndrome. Nursing \& health sciences. 2013;15(3):273-9.

[29]. Rumsfeld JS, Magid DJ, Plomondon ME, O’Brien MM, Spertus JA, Every NR, et al. Predictors of quality of life following acute coronary syndromes. The American journal of cardiology. 2001;88(7):781-4.

[30]. Maddox TM, Reid KJ, Rumsfeld JS, Spertus JA. One-year health status outcomes of unstable angina versus myocardial infarction: a prospective, observational cohort study of ACS survivors. BMC cardiovascular disorders. 2007;7:28.

[31]. Bode C, Zirlik A. STEMI and NSTEMI: the dangerous brothers. European heart journal. 2007;28(12):1403-4.

[32]. Kim M-J, Jeon DS, Gwon H-C, Kim S-J, Chang K, Kim H-S, et al. Health-related quality-of-life after percutaneous coronary intervention in patients with UA/NSTEMI and STEMI: The Korean multicenter registry. Journal of Korean medical science. 2013;28(6):848-54.

[33]. Dias CMCC, Macedo LB, Gomes LTJC, de Oliveira PLSP, Albuquerque IVS, Lemos AQ, et al. Quality of Life of Patients After an Acute Coronary Event: Hospital Discharge. Journal of Clinical Medicine Research. 2014;6(5):362-8.

[34]. De Smedt D, Clays E, Annemans L, Pardaens S, Kotseva K, De Bacquer D. Risk factor awareness in a coronary population and the association with health-related quality of life outcomes. International Journal of Public Health. 2014;59(3):475-83.

[35]. Hemingway H, Langenberg C, Damant J, Frost C, Pyorala K, Barrett-Connor E. Prevalence of angina in women versus men: a systematic review and meta-analysis of international variations across 31 countries. Circulation. 2008;117(12):1526-36.

[36]. Veenstra M, Pettersen KI, Rollag A, Stavem K. Association of changes in health-related quality of life in coronary heart disease with coronary procedures and sociodemographic characteristics. Health and Quality of Life Outcomes. 2004;2(1):1-8.

[37]. Alter DA, Naylor CD, Austin P, Tu JV. Effects of socioeconomic status on access to invasive cardiac procedures and on mortality after acute myocardial infarction. New England Journal of Medicine. 1999;341(18):1359-67.

[38]. Pagidipati NJ, Peterson ED. Acute coronary syndromes in women and men. Nature reviews Cardiology. 2016;13(8):471-80.

[39]. Grace SL, Krepostman S, Brooks D, Arthur H, Scholey P, Suskin N, et al. Illness perceptions among cardiac patients: relation to depressive symptomatology and sex. Journal of psychosomatic research. 2005;59(3):153-60.

[40]. Bergvik S, Sørlie T, Wynn R. Coronary patients who returned to work had stronger internal locus of control beliefs than those who did not return to work. British Journal of Health Psychology. 2012;17(3):596-608.

[41]. Leslie SJ, Rysdale J, Lee AJ, Eteiba H, Starkey IR, Pell J, et al. Unemployment and deprivation are associated with a poorer outcome following percutaneous coronary angioplasty. International Journal of Cardiology. 2007;122(2):168-9.

[42]. Souza EN, Quadros AS, Maestri R, Albarrán C, Sarmento-Leite R. Predictors of quality of life change after an acute coronary event. Arquivos brasileiros de cardiologia. 2008;91(4):252-9.

[43]. Lalonde L, Clarke AE, Joseph L, Mackenzie T, Grover SA. Health-related quality of life with coronary heart disease prevention and treatment. Journal of clinical epidemiology. 2001;54(10):1011-8.

[44]. Dias CC, Mateus P, Santos L, Mateus C, Sampaio F, Adão L, et al. Acute coronary syndrome and predictors of quality of life. Revista portuguesa de cardiologia: orgão oficial da Sociedade Portuguesa de Cardiologia= Portuguese journal of cardiology: an official journal of the Portuguese Society of Cardiology. 2005;24(6):819-31.

[45]. Krintus M, Koziński M, Kuligowska-Prusińska M, Laskowska E, Janiszewska E, Kubica J, et al. The performance of triglyceride to high-density lipoprotein cholesterol ratio in acute coronary syndromes using a diagnostic decision tree. Folia Medica Copernicana. 2015;3(1):13-9.

[46]. Montalescot G, Dallongeville J, Van Belle E, Rouanet S, Baulac C, Degrandsart A, et al. STEMI and NSTEMI: are they so different? 1 year outcomes in acute myocardial infarction as defined by the ESC/ACC definition (the OPERA registry). European heart journal. 2007;28(12):1409-17.

[47]. Leon AS, Bronas UG. Dyslipidemia and risk of coronary heart disease: Role of lifestyle approaches for its management. American journal of lifestyle medicine. 2009;3(4):257-73

[48]. Yuval R, Halon DA, Lewis BS. Perceived disability and lifestyle modification following hospitalization for non-ST elevation versus ST elevation acute coronary syndromes: the patients' point of view. European Journal of Cardiovascular Nursing. 2007;6(4):287-92

[49]. De Smedt D, Clays E, Annemans L, Doyle F, Kotseva K, Pająk A, et al. Health related quality of life in coronary patients and its association with their cardiovascular risk profile: results from the EUROASPIRE III survey. International journal of cardiology. 2013;168(2):898-903 
[50]. Sevinc S, Akyol AD. Cardiac risk factors and quality of life in patients with coronary artery disease. Journal of clinical nursing. 2010;19(9- 10):1315-25.

[51]. Carlsson R. Serum cholesterol, lifestyle, working capacity and quality of life in patients with coronary artery disease. Experiences from a hospital-based secondary prevention programme. Scandinavian Cardiovascular Journal. 1998;32(50):1-20.

[52]. Chow CK, Jolly S, Rao-Melacini P, Fox KA, Anand SS, Yusuf S. Association of diet, exercise, and smoking modification with risk of early cardiovascular events after acute coronary syndromes. Circulation. 2010;121(6):750-8.

[53]. Nilsson E. Aspects of health-related quality of life: Associations with psychological and biological factors, and use as patient reported outcome in routine health care. 2012.

[54]. Goff DC, Lloyd-Jones DM, Bennett G, O'Donnell C, Coady S, Robinson J. 2013 ACC/AHA guideline on the assessment of cardiovascular risk. J Am Coll Cardiol. 2014.

[55]. Preedy VR, Watson RR. Handbook of disease burdens and quality of life measures: Springer New York; 2010.

[56]. Niedziela J, Hudzik B, Niedziela N, Gąsior M, Gierlotka M, Wasilewski J, et al. The obesity paradox in acute coronary syndrome: a meta-analysis. European journal of epidemiology. 2014;29(11):801-12.

[57]. Perk J, De Backer G, Gohlke H, Graham I, Reiner Ž, Verschuren M, et al. European Guidelines on cardiovascular disease prevention in clinical practice (version 2012). European heart journal. 2012;33(13):1635-701.

[58]. Rawas HO. The second chance project: A multi-level examination of secondary prevention practices for Saudi people following a recent cardiac event. 2015.

[59]. Tahir Durmaz ÖÖ, Burcu Akyunak Özdemir, Telat Keles, Nihal Akar Bayram \& Engin Bozkurt. Factors affecting quality of life in patients with coronary heart disease. 2009.

[60]. Kramer L, Hirsch O, Schloessler K, Träger S, Baum E, Donner-Banzhoff N. Associations between demographic, disease related, and treatment pathway related variables and health related quality of life in primary care patients with coronary heart disease. Health and Quality of Life Outcomes. 2012;10(78):10.1186.

[61]. Ammouri AA, Neuberger G, Mrayyan MT, Hamaideh SH. Perception of risk of coronary heart disease among Jordanians. Journal of clinical nursing. 2011;20(1- 2):197-203.

[62]. Tchicaya A, Lorentz N, Demarest S, Beissel J, Wagner DR. Relationship between self-reported weight change, educational status, and health-related quality of life in patients with diabetes in Luxembourg. Health and quality of life outcomes. 2015;13(1):1. 